\title{
CARLOS IV Y EL DUCADO DE PARMA EN TIEMPOS DE REVOLUCIÓN (1796-1801), CON EL TRASFONDO DE LA CUESTIÓN DE LA LUISIANA
}

\author{
AinOA CHINCHILla GALARZO ${ }^{1}$ \\ Universidad Complutense de Madrid \\ ainochin@ucm.es \\ http://orcid.org/0000-0002-8397-9327
}

\section{Resumen}

Como bien conocemos, desde el siglo XVI, las relaciones entre el ducado de Parma y la monarquía española fueron muy intensas, algo que vino a potenciarse con la llegada de la Revolución francesa y que se materializó en el Tratado de Basilea de julio de 1795, por el que se establecía la mediación del rey de España a favor del ducado de Parma. Desde ese momento, dicho territorio se convertía en uno de los intereses primordiales de Carlos IV. Por consiguiente, el presente trabajo pretende resaltar las relaciones que, como potencia mediadora, ejerció España, así como la utilización de este ducado como ficha en el tablero diplomático europeo por parte del gobierno francés. Un territorio que fue usado de forma recurrente por el gabinete galo para presionar a su homólogo español y que siempre suele ir ligado a la exigencia francesa de la cesión de Luisiana por parte de España. Por ello, pretendemos analizar una negociación larga en el tiempo, desde la primera propuesta de 1796 a la final firma del Tratado de Aranjuez en 1801, que sufre continuas pausas ligadas al devenir de los tiempos revolucionarios y de la misma forma dar a conocer los numerosos actores que intervinieron en ella, destacando el importante papel de la corrupción.

Palabras clave: Mediación, corrupción, Luisiana, María Luisa de Parma, diplomacia

1. Este trabajo se ha realizado con la ayuda de un contrato predoctoral de Formación de Profesorado Universitario (FPU17/00717) otorgado por el Ministerio de Educación, Cultura y Deporte y con el inestimable apoyo de mis directores de tesis José Cepeda Gómez y María Dolores Herrero Fernández-Quesada. 
Carlos IV and the duchy of Parma in times of revolution (1796-1801), with the background of the question of the Louisiana

\begin{abstract}
As we know, since the sixteenth century, the relations between the duchy of Parma and the Spanish monarchy were very intense, something that came to intensify with the French Revolution and that materialized in the Treaty of Basel of July 1795, by which the mediation of the king of Spain in favour of the duchy of Parma established. From that moment, the duchy of Parma became one of the primary interests of Carlos IV. Therefore, this paper aims to highlight the relationships that, as a mediating power, exercised by Spain, and the use of this duchy as a piece on the European diplomatic board by the French government. A territory in which French politics used recurrently to put pressure on the Spanish and which it was always used to be linked to the French demand for the cession of Louisiana by Spain. Therefore, we intend to analyse a long negotiation in time, from the first proposal of 1796 to the final signing of the Treaty of Aranjuez in 1801, which suffers continuous breaks linked to the evolution of revolutionary times. And showing the many actors that intervened in it, highlighting the important role of corruption.
\end{abstract}

Keywords: Mediation, corruption, Louisiana, María Luisa de Parma, diplomacy

\title{
Introducción
}

Desde el siglo XVI hasta la desaparición del ducado de Parma y la creación del nuevo reino de Etruria por Napoleón Bonaparte en el antiguo ducado de Toscana, los vínculos entre dicho territorio y la monarquía española fueron muy intensos. Algo que vino a potenciarse con la llegada de la Revolución Francesa y que se materializó en el Tratado de Basilea, por el que se establecía la mediación de Carlos IV a favor del duque. El citado acuerdo mostraba el particular interés del monarca hacia el Estado parmesano con el que mantenía amplios nexos familiares. A partir de mediados del XVIII, la política de alianzas matrimoniales de la casa reinante y la ducal provocaría una mayor familiaridad entre las dos dinastías, ya que Fernando de Parma era hermano de la reina consorte de España, María Luisa. Precisamente, la primera parte del artículo se centrará en el análisis de las relaciones diplomáticas entre ellas, para poder entender las dinámicas posteriores que aclararán la inclinación de los monarcas españoles por el engrandecimiento de esta pequeña nación italiana. 
Las posesiones parmesanas se convertirán, a partir de 1795, en uno de los intereses primordiales de Carlos IV. Por lo tanto, en la segunda sección de este trabajo se pretende resaltar las relaciones que España mantuvo, en su posición de potencia mediadora, en el momento en el que los ejércitos revolucionarios estaban conquistando la península itálica. Del mismo modo se quiere destacar la utilización del Estado parmesano como ficha en el tablero diplomático europeo por parte de Francia. Unas negociaciones que suelen encasillarse en la firma del tratado de acrecentamiento y la entrega de la Luisiana, y que reivindicamos como un tema anterior en el tiempo. Una región, la de Parma, que fue usada de forma recurrente por los distintos gobernantes galos desde 1796 para presionar al gabinete madrileño y cuyo aumento territorial siempre fue ligado a la exigencia francesa de cesión de la Luisiana.

En tercer lugar, este trabajo se ocupará del posible aumento de los territorios parmesanos ligado a los intereses de la política internacional del momento y sobre todo al objetivo galo de dominar Italia y obtener posesiones en el continente americano, mediante la ocupación del territorio parmesano fronterizo a la República Cisalpina y la cesión de algunos dominios españoles en América del Norte. Finalmente, nos gustaría acentuar el uso de la diplomacia oficiosa y las corruptelas, del mismo modo que poner en valor el enérgico papel de la reina española en las negociaciones para el engrandecimiento de Parma, sin olvidar el hecho de que la influencia y el poder que ejercía la potencia francesa fueron los que obligaron a Carlos IV y al duque Fernando a aceptar sus exigencias.

Por último, concretamos que el período cronológico que vamos a abarcar va desde la primera propuesta francesa de intercambio en 1796 a la firma del Tratado de Aranjuez en 1801, pasando por los preliminares de San Ildefonso y los sucesivos avatares de estas conversaciones diplomáticas, que sufren continuas pausas ligadas al devenir de los tiempos revolucionarios. También nos interesa dar a conocer los numerosos actores que intervinieron en ella y apuntar que en este artículo hemos utilizado la información custodiada en el Archivo Histórico Nacional de Madrid y en los Archives du Ministère des Affaires Étrangères y los Archives Nationales de Francia. 


\section{Recorrido de las relaciones entre España y el ducado de Parma: interés primordial de los reyes españoles}

El interés español por el ducado de Parma comenzó en el siglo XVI, en el transcurso de las guerras entre España y Francia en suelo italiano en las que también intervino el Papado. Una disputa que terminaría con la devolución del mismo por Felipe II en 1556. Sería al comienzo del reinado de Felipe V cuando este Estado regresaría a las miras de la corte española con la política italiana llevada a cabo por la reina Isabel de Farnesio, quien consiguió poner a uno de sus hijos en el gobierno ducal, tras la muerte del último heredero sin descendencia. El infante Carlos gobernaría el territorio parmesano hasta la guerra de sucesión de Polonia, momento en que los Habsburgo reclamaron sus derechos sobre dicho lugar que les fueron devueltos a cambio del reino de las Dos Sicilias².

La gobernación hasbúrgica duraría muy poco puesto que otro conflicto, el de Sucesión austriaco, provocaría la vuelta a manos de los Borbones de este pequeño territorio con el infante Felipe, hijo de Felipe V e Isabel de Farnesio. Tiempo después, el duque ayudaría a estrechar aún más los lazos con su dinastía de origen gracias al enlace de su hija María Luisa de Parma con el heredero de la monarquía española, Carlos de Borbón, en 1765, quienes tras un largo período como príncipes de Asturias se convertían en reyes de España en 1788. La casa Borbón-Parma se mantuvo en el gobierno ducal durante los años que nos ocupan con Fernando, hermano de la reina española, quien siguió la misma estrategia basada en las alianzas matrimoniales entre las dos familias. En 1795 se producía la unión de la infanta María Luisa, con el sucesor del Estado parmesano, Luis de Borbón. Ellos vivirían la conversión del ducado en reino, convirtiéndose en los nuevos monarcas de Etruria ${ }^{3}$.

Tras las breves pinceladas que explican la predisposición que los monarcas españoles siempre habían manifestado sobre la casa ducal de Parma, tenemos que afirmar que a finales del Antiguo Régimen dicha tendencia se verá

2. POMPONI, 2013: 41-42. RAO, 2003a: 587.

3. Pomponi, 2013: 41-42. Calvo Maturana, 2007: 11-130. EsPadas Burgos, 2013: 63-64. Berte-Langereau, 1958: 4-6. Archivo Histórico Nacional (en adelante AHN), Ministerio de Asuntos Exteriores, Santa Sede, Leg. 366. Nota que anuncia el matrimonio entre María Luisa de Borbón y Luis de Borbón-Parma. 
intensificada. Para Carlos IV la particular predilección por el ducado pivotaba, por un lado, entre la necesidad de sostener la monarquía como forma de gobierno, es decir, evitar el menoscabo en la autoridad real y en su modo de ejercer el poder, en un intento de alejarse de los acontecimientos revolucionarios ocurridos en Francia y, por otro lado, mantener la integridad de todas las posesiones hispánicas y defender la religión católica y, por tanto, la Santa Sede. A estas inclinaciones generales se les unían unos intereses dinásticos vinculados con el anhelo de la corona por intervenir y fomentar unas buenas relaciones diplomáticas en las regiones gobernadas por sus familiares directos. El primero de ellos fue el engrandecimiento del ducado de Parma, que era lugar de origen de la reina María Luisa. El reino de Nápoles era el segundo Estado que también preocupaba a los reyes. Su máxima consistía en conservar la influencia de la corte madrileña en los dominios del hermano del rey, Fernando IV. En tercer lugar estaba Portugal, que se encontraba en una situación muy similar a la de Parma, ya que en él residía una infanta española, Carlota Joaquina, unida en matrimonio al príncipe portugués don Juan desde $1785^{4}$.

Estos objetivos dinásticos obedecían a un concepto y una política bastante arcaizantes que se habían prolongado a lo largo de todo el siglo XVIII y que siempre dependieron de las relaciones con las dos potencias principales del escenario diplomático: Francia e Inglaterra. La línea que la diplomacia hispánica siguió durante toda esta centuria fue la del acercamiento a la potencia francesa para hacer frente al imperio austriaco, debido a los intereses de casi todos los monarcas españoles en las posesiones italianas, especialmente Felipe V, Carlos III y Carlos IV 5 . La búsqueda de la citada injerencia tenemos que relacionarla con la firma de tres pactos de familia en 1733, 1743 y 1761 por los reyes hispánicos, a excepción de Fernando VI. La idea de protección sobre los Estados italianos estaba férreamente incrustada a finales del reinado de Carlos III, tanto que el sentido del apego español por los mismos será expresado por el secretario de Estado, el conde de Floridablanca, en su Instrucción Reservada: «un interés general e indirecto respecto a la Italia entera puede ocupar en algún tiempo los cuidados de la España, si alguna

4. Chinchilla Galarzo, 2018: 684. La Parra López, 2009: 44-45.

5. SeCo Serrano, 1988: 569-570. La Parra López, 2003: 230. 
potencia poderosa intentare invadir y subyugar los estados $»^{6}$. Con la llegada al trono de Carlos IV y María Luisa de Parma, el territorio italiano retomará su importancia en la política exterior española. Un propósito que va estar ligado constantemente a la ambición conquistadora de los gobernantes revolucionarios tendrán en la península itálica, que solo coincidía con el gabinete madrileño en su deseo de eliminar la influencia austriaca ${ }^{7}$.

Por otro lado, tenemos que enfatizar, como bien han hecho autores de la talla de Carlos Seco Serrano o Emilio La Parra, que la política exterior española con respecto al ducado de Parma no estuvo tan controlada por el secretario de Estado, Manuel Godoy, como por el propio Carlos IV, quien siempre contó con la ayuda y el consejo de la reina María Luisa. La influencia de esta última en la diplomacia llevada a cabo por el monarca fue primordial para el desarrollo de los acontecimientos ligados al territorio parmesano y a su más que deseado engrandecimiento. Su papel en el ámbito diplomático fue activo y con gran capacidad de decisión ante la corte madrileña y los embajadores extranjeros ${ }^{8}$.

Sin embargo, este deseo de los monarcas y en especial de la reina solo podría conseguirse con el apoyo del gobierno que estaba conquistando dicho territorio: el Directorio francés. Volvía a repetirse la dinámica seguida durante todo el siglo XVIII; para poder mantener la influencia española en los espacios italianos se necesitaba la ayuda de Francia. Debido a esto, en el Tratado de Basilea firmado en julio de 1795 se especificaba el afán de los reyes españoles por ejercer una especie de mediación para con algunos Estados de Italia y Portugal. Una predilección que se materializó en el artículo XV del convenio: «La República Francesa, queriendo dar un testimonio de amistad a Su Majestad Católica, acepta su mediación a favor de la reina de Portugal, del rey de Nápoles, del rey de Cerdeña, del infante duque de Parma y de otros Estados de Italia, para el restablecimiento de la paz entre la República y cada uno de esos príncipes y Estados» ${ }^{9}$.

6. Ruiz Alemán, 1982: 236.

7. LA PARRA LÓPEZ, 1992: 44-45.

8. LA PARRA LÓPEZ, 2003: 223; 1992: 76-77.

9. AHN, Estado, Leg. 3401. Tratado de paz entre España y Francia firmado en Basilea, 22 de julio de 1795 . 
Un convenio que uniría desde ese instante la política del ducado de Parma y la de España hasta $1808^{10}$. Sin embargo, el papel de mediador reconocido a Carlos IV en Basilea se vería muy reducido en la práctica por los objetivos militares del gabinete francés, sobre todo a partir de marzo de 1796, cuando las conquistas de Napoleón en Italia conviertan a estos lugares en piezas claves del tablero diplomático del momento. Por consiguiente, la estrategia del ministro español pretendía la vuelta a la dinámica de la alianza con Francia, mediante un Pacto de Familia, pero sin familia que permitiese un mayor margen de injerencia de los monarcas, Carlos y María Luisa, en los asuntos parmesanos ${ }^{11}$.

\section{Inicio de la mediación y primeras propuestas de engrandecimiento}

Tras la firma del Tratado de Basilea, la cuestión de Parma no tardó en aparecer en los asuntos diplomáticos hispano-franceses. El ministro de Estado, Manuel Godoy y los monarcas querían saber cuál era la posición en la que se encontraba el ducado, ¿estaba Francia en paz con Parma o en estado de beligerancia? La República Francesa no parecía querer dar el primer paso, pidiendo al rey español que explicase la situación del duque Fernando, y advirtiéndole que hasta que no obtuviese dicha aclaración obraría hostilmente contra dicho infante. Después de las presiones hacia Carlos IV, el gabinete francés finalmente decidió considerarse en estado de paz con respecto a Parma. Desde entonces empezaría la política algo errática del Directorio en relación al territorio parmesano ${ }^{12}$.

Así se abría un breve periodo de tranquilidad que no obligaba al monarca español a ejercer su mediación en favor de Parma, con lo que pudo dedicarse a las negociaciones para coaligarse con Francia. No obstante, esta estabilidad vendría a romperse con la irrupción de Napoleón Bonaparte en las campañas italianas. En mayo de 1796 las huestes francesas, al mando del general

10. SECO SERRANO, 1978: 130-131. GIMÉNEZ LÓPEZ, 1996: 60-61.

11. RaO, 2003b: 304-310. LA PARRA LÓPEZ, 1992: 27-49. POMPONI, 2013: 41-42. CHINCHILla GALARZO, 2018: 681-684.

12. AHN, Estado, Leg. 3404. Cartas de Domingo de Iriarte, plenipotenciario español en Basilea a Manuel Godoy, secretario de Estado español, Basilea, 27 de agosto y 18 de septiembre de 1795. AHN, Estado, Leg. 3401. Carta de Domingo de Iriarte a Manuel Godoy, Basilea, 3 de septiembre de 1795. BerTE-LANGEREAU, 1958: 6-8. 
Lannes entraban en territorio parmesano, puesto que el gobierno francés consideraba que el duque formaba parte de la coalición antirrevolucionaria. La argumentación del Directorio no era muy descabellada ya que Fernando había firmado un tratado secreto de alianza con Austria, aunque no había movilizado a sus tropas ${ }^{13}$; y pese a los sucesivos intentos de la diplomacia española presente en París, en las cuestiones parmesanas parecía no caber la intercesión de los reyes. Las vejaciones hacia los dominios ducales se sucedían mientras que los miembros del Directorio desoían el anhelo de arbitraje de la corte de Madrid y pedían que plenipotenciarios parmesanos viniesen a tratar la paz a la capital gala ${ }^{14}$.

Esta situación encuentra su razón de ser en el hecho de que la diplomacia francesa empezó a tomar nuevos cauces y nuevas formas de negociación. En esta coyuntura, se dejaría de lado la mediación española, siendo el propio general Bonaparte el que negociaría un armisticio con el infante duque evitando así la injerencia de los monarcas. Por dicho pacto se estipulaba el pago de una indemnización de dos millones de libras, diversos animales de tiro y unos veinte cuadros. Las altas exigencias provocaron que poco tiempo después se comenzase a hablar de negociar una paz, en un intento de rebajar las cláusulas anteriormente mencionadas. Aquí tampoco conseguiría España ejercer su influencia; aunque Fernando de Parma autorizó a Bernardo del Campo, embajador español en París, para comenzar a tratar la paz, el Directorio francés le negó su derecho. La impresión que Campo transmitió a Godoy sobre la poca importancia que Francia daba a la preocupación de los reyes por el asunto parmesano decía así: «salió por la ventana porque no pudo por la puerta» ${ }^{15}$.

13. AHN, Estado, Leg. 4005. Cartas de Bernardo del Campo, embajador español en París a Manuel Godoy, París, 5 y 7 de mayo de 1796. EsPADAS Burgos, 2013: 64-65. CORONA BARATECH, 1948: 36-37. BERTE-LANGEREAU, 1958: 8.

14. AHN, Estado, Leg. 4005. Carta de Manuel Godoy a Bernardo del Campo, Aranjuez, 23 de mayo de 1796 y cartas de Bernardo del Campo a Manuel Godoy, París, 8 y 10 de mayo de 1796. Archive du Ministère des Affaires Étrangères (en adelante AMAE), Correspondance politique Parme, vol. 46. Memoria de Bernardo del Campo al Directorio Ejecutivo, París, 5 de mayo de 1796 y respuesta del Directorio, París, 18 de floreal año IV (7 de mayo de 1796). LA PARRA LóPEZ, 1992: 45-46. FugIER, 2008: 88-90.

15. AHN, Estado, Leg. 4005. Cartas de Bernardo del Campo a Manuel Godoy, París, 17, 19, 21 y 27 de mayo de 1796. AMAE, Correspondance politique Parme, vol. 46. Carta

Revista de Historia Moderna, n. ${ }^{\circ} 37$ (2019) (pp. 65-93) | ISSN-e: 1989-9823 | ISSN: 0212-5862 
Con la entrada del verano las cosas no parecían mejorar, pues mientras que el embajador Campo luchaba por conseguir activar la mediación y una mejora de las condiciones del armisticio firmado por el duque de Parma, el gobierno galo respondía de forma muy dura. En primer lugar, los directores contestaban que la suma pecuniaria, que tanto se esforzaban en bajar los ministros españoles, se debía a los enormes gastos del ejército que combatía por su defensa contra una región, la parmesana, que no había sido rozada hasta el momento. La realidad es que Francia se hallaba agotada económicamente por el esfuerzo bélico en otros espacios europeos. En segundo lugar, cuando comenzó a hablarse en París de negociar la paz entre el ducado y la potencia francesa, Bernardo del Campo se encontró con las puertas cerradas. Fue el ministro francés de Asuntos Exteriores el que le apartó de las negociaciones, aludiendo que existía una incompatibilidad absoluta entre sus funciones como negociador del infante y las de mediador en nombre del rey de España. Al representante español no le quedó otra salida que aguardar la llegada de los plenipotenciarios parmesanos y aconsejarles ${ }^{16}$.

Pronto surgió una nueva proposición ligada a las negociaciones de alianza entre Francia y España que en esos momentos se estaban llevando a cabo en Madrid. En primer lugar, ofrecieron al ministro Godoy salvar las posesiones ducales -e incluso engrandecerlas- si la escuadra española protegía a la del almirante Richery en su salida, pues se encontraba bloqueada en el Mediterráneo por los ingleses. Algo que el gobierno español cumplió como muestra de su buena intención hacia el Directorio. En segundo lugar, se produjo la propuesta inicial del gabinete francés para engrandecer los Estados

de Charles Delacroix, ministro de asuntos exteriores francés a François Pérignon, embajador francés en Madrid, Madrid, 20 de floreal año IV (19 de mayo de 1796), memorias de Bernardo del Campo a Charles Delacroix, París, 20 y 26 de mayo de 1796 y carta de Fernando de Borbón, duque de Parma al Directorio Ejecutivo, s.l. 26 de mayo de 1796. BERTE-LANGEREAU, 1958: 8-11.

16. AHN, Estado, Leg. 6667. Cartas de Charles Delacroix a Bernardo del Campo, París, 21 de mayo y 3 de junio de 1796, carta de Bernardo del Campo a Charles Delacroix, París, 2 de junio de 1796 y carta del conde de Valparaíso, ministro plenipotenciario español en Parma a Bernardo del Campo, Parma, 26 de mayo de 1796. AMAE, Correspondance politique Parme, vol. 46. Memoria de Bernardo del Campo a Charles Delacroix, París, 2 de junio de 1796 y contestación de Delacroix a Bernardo del Campo, París, 15 prairial año IV (3 de junio de 1796). BERTE-LANGEREAU, 1958: 14-16. 
del duque. Delacroix comenzó por ofrecer la Lombardía, pero el infante se planteaba que sería muy peligroso acceder sin causar un enfrentamiento con el emperador austriaco que era su sobrino. Fernando sugería otras opciones: llegar a la paz con los franceses y que estos, con ayuda de los españoles, se hiciesen con el ducado de Milán y después se lo cediesen a él o que le entregasen los dominios del duque de Módena una vez que este falleciese; aun así para él lo más importante no era conseguir más territorios sobre los que gobernar, sino conservar los propios ${ }^{17}$.

La estrategia del Directorio consistía en utilizar los dominios parmesanos a modo de moneda de cambio para conseguir ventajas del gobierno español. Concretamente, fue durante las negociaciones finales de la alianza entre estas dos potencias cuando el embajador francés planteó el engrandecimiento. Los directores se comprometían a ceder a Fernando gran parte del ducado de Milán, así como Castro y Ronciglione (territorios enclavados entre Génova y Luca) y además incluían la posibilidad de entregar el ducado de Mantua una vez que su señor falleciera, pero esto no saldría gratis ni a España, ni a Parma $^{18}$.

Si la corte madrileña aceptaba engrandecer los Estados del duque debería transferir a los franceses la Luisiana y la Florida en el continente americano y varias poblaciones enclavadas en Cataluña y en la Cerdaña francesa, no sin antes aceptar las cláusulas a las que más impedimento estaba poniendo el ministro Godoy: un tratado de comercio hispano-francés, alejar a los emigrados galos de las zonas de puerto y frontera y comprometerse a conseguir el cierre de puertos portugueses a los ingleses - esta última fue la única concesión que obtendrían-. Por otro lado, a Fernando de Parma se le obligaba a pagar seis millones de francos anualmente por los gastos derivados de la guerra, siendo garante el monarca español. Obviamente, estas condiciones no fueron aceptadas por ninguno de los dos gobiernos ${ }^{19}$.

17. AHN, Estado, Leg. 3404. Carta de Manuel Godoy a François Pérignon, San Ildefonso, 20 de julio de 1796. BERTE-LANGEREAU, 1958: 16-20.

18. AHN, Estado, Leg. 3404. Carta de Manuel Godoy a François Pérignon, San Ildefonso, 20 de julio de 1796. La PARRA López, 1992: 47-48.

19. AHN, Estado, Leg. 3404. Carta de Manuel Godoy a François Pérignon, San Ildefonso, 10 de agosto de 1796. Archives Nationales de France (en adelante ANF), serie AF/III, 
El asunto del engrandecimiento de Parma se convertía desde ese instante en una pieza más del tablero diplomático en el que debían jugar Francia y España. Una ficha que la primera utilizará en diversos momentos de su intricada relación, para presionar al gobierno español en su afán por controlar ciertos lugares en América como Santo Domingo, la Florida o la Luisiana. En esta coyuntura, la cuestión parmesana sirvió para coaccionar al rey y a Godoy y conseguir la alianza. Por otro lado, tras la unión de las dos potencias en San Ildefonso la política española con respecto a los territorios del infante se concentrará en su conservación tal y como estaban, sin que sufriesen detrimento, obtener una paz razonable y prolongar su influencia sobre el ducado, ya que la potencia que comenzaba a dominar los Estados italianos era la República Francesa ${ }^{20}$.

Desde ese momento, la consecución de la paz para el hermano de la reina María Luisa se convertiría en un gran escollo en las relaciones diplomáticas hispano-francesas; así de crudas eran las palabras de Bernardo del Campo: «bellas ofertas, pero se lleva adelante el sistema arbitrario de llevárselo todo de calle». En el verano, las conversaciones de paz entre París y Parma habían quedado en un punto muerto debido a la insistencia del Directorio de incluir artículos referentes a las cuestiones comerciales. Tanto para España como para el duque, la cuestión comercial no tenía sentido en un convenio de paz. Simplemente era un intento por parte de los franceses para afrontar los enormes gastos que suponía mantener tantos frentes de guerra abiertos ${ }^{21}$. En septiembre Campo conseguía un nuevo avance en las negociaciones y la paz entre Francia y Parma se firmaba el 5 de noviembre de 1796, aunque sin

vol. 56. Cuenta decadaria, 1796. FUGIER, 2008: 39-40. BÉCKER, 2006: 10. LA PARRA LÓPEZ, 1992: 48-49. RAO, 2003b: 305.

20. LA PARRA López, 2005: 143; 1992: 49. GimÉnEZ LóPEZ, 2001: 64-65.

21. AHN, Estado, Leg. 3998. Cartas de Bernardo del Campo a Manuel Godoy, París, 20 y 26 de julio, 27 de agosto y 3 de septiembre de 1796. AHN, Estado, Leg. 6667. Carta confidencial de Bernardo del Campo al conde de Valparaíso, París, 22 de julio de 1796 y carta del conde de Valparaíso a Bernardo del Campo, s. l. 6 de agosto de 1796. AHN, Estado, Leg. 6668. Carta de Bernardo del Campo a Manuel Godoy, París, 12 de agosto de 1796. AMAE, Correspondance politique Parme, vol. 46. Varios proyectos de tratados comerciales entre el ducado de Parma redactados por el Directorio Ejecutivo, París, s.f. y unas memorias de Bernardo del Campo, conde Politi y Luis Bolla, plenipotenciarios parmesanos, París, 1 y 29 de julio de 1796. 
recuperar los preciados cuadros del duque. Este acuerdo no proporcionaba ventajas, si consideramos que Fernando nunca acometió acciones hostiles contra Francia. Finalmente, el infante no dejaba representación diplomática en la capital francesa y nombraba al plenipotenciario español como su comisionado ante la República; en Parma quedaba José Bonaparte ${ }^{22}$.

\section{El posible engrandecimiento y los problemas con la República Cisalpina}

Tras la firma de la paz franco-parmesana, la posición del duque no hacía más que agravarse. A la presión ejercida por los ejércitos revolucionarios se añadía la creación de República Cisalpina mediante la unión del Milanesado, el ducado de Módena, las legaciones pontificias y una parte de Venecia. Esta situación provocaba una sensación de permanente alerta tanto para el gobierno de España como de Parma, que veían peligrar la integridad del territorio ante la agresividad y la capacidad de conquista de los franceses en la península itálica ${ }^{23}$. No tardarían en llegar las propuestas para abandonar el ducado del general Bonaparte, el verdadero dominador de los territorios italianos, deseoso por crear un Estado fuerte dependiente de Francia en el norte de Italia para impedir la influencia de los austriacos.

En la primavera de 1797, las proposiciones de Bonaparte se centraban en dividir los Estados del infante y anexionar una parte de ellos a la República Cisalpina y con la otra contentar al rey de Cerdeña o, en su caso, conseguir la zona del Ultra Po para la nueva república. Esta cesión se compensaría al darle la Romaña al duque Fernando e incluso se insinuó una nueva denominación para el duque: rey de Roma, propuesta esta última que conecta totalmente con la posterior creación del reino de Etruria, cuando Napoleón se convierta

22. AHN, Estado, Leg. 4424. Carta del conde Ventura, primer ministro del ducado de Parma a Manuel Godoy, Parma, 20 de noviembre de 1796. AHN, Estado, Leg. 3998. Cartas de Bernardo del Campo a Manuel Godoy, París, 6 de noviembre, 1 y 4 de diciembre de 1796. AMAE, Correspondance politique Parme, vol. 46. Proyecto de tratado de paz entre Francia y el ducado de Parma y observaciones, París, 25 de octubre de 1796. FUGIER, 1967: 881; 2008: 39-40. BERTE-LANGEREAU, 1958: 26-31. ESPADAS BuRGOS, 2013: 64-65.

23. AHN, Estado, Leg. 4451. Carta del conde Politi, comisionado por el duque de Parma cerca de Napoleón Bonaparte, al conde Ventura, Milán, 31 de mayo de 1797. BERTELANGEREAU, 1958: 40-41. LA PARRA LÓPEZ, 1992: 48-49. 
ya en Primer Cónsul de Francia, por lo que podemos decir que la idea de crear un reino para el duque de Parma ya estaba en la mente del general ${ }^{24}$.

Esta situación provocaba de nuevo la entrada en escena de la mediación de Carlos IV y María Luisa, que debían conseguir que no se alterasen los dominios de la casa ducal, aunque las propuestas ya habían llegado antes a la corte madrileña que a la parmesana. El embajador francés en Madrid volvía ofrecer el engrandecimiento del ducado de Parma, ligado a la cesión de la Luisiana y la Florida a la república, pero Godoy se negaba por activa y por pasiva a darles algún palmo de tierra americana y por ello dejó atrás este tema hasta la llegada del verano ${ }^{25}$. En este lapso de tiempo llegarían las ofertas más serias por parte del gobierno español, ya que temían la gran exposición que Fernando sufría en sus posesiones, entre las nuevas repúblicas y Génova, sin apenas contar con defensa militar. Debido a esto, tanto Francisco Cabarrús como Bernardo del Campo, plenipotenciarios para las negociaciones de paz en Lille, pensaban que lo más conveniente para el duque sería negociar con Francia la permuta de sus territorios, para alejarlo en todo lo posible del escenario de la guerra ${ }^{26}$.

Cabarrús creía que lo mejor sería trocar los Estados del duque por los del rey de Cerdeña. Un cambio muy beneficioso para las pretensiones del gabinete madrileño, ya que se contaría con un enclave en el centro del Mediterráneo desde el cual controlar la navegación y el comercio. Además, para el hermano de la reina significaría alejarse del teatro bélico. No obstante, tenemos que recordar que estas proposiciones se insertan en el escenario de las conversaciones de paz general con Inglaterra en Lille. Un congreso en el que no se aceptaron a los plenipotenciarios de las potencias aliadas y donde Gran Bretaña y Francia conversaron sin escucharlas. Esto provocó que el gobierno español se viese obligado a emprender una vía propia de negociación de la

24. AHN, Estado, Leg. 4451. Carta del conde Politi, comisionado por el duque de Parma cerca de Napoleón Bonaparte, al conde Ventura, Milán, 31 de mayo de 1797. BERTELANGEREAU, 1958: 42-44.

25. AHN, Estado, Leg. 6670. Carta de François Pérignon a Manuel Godoy, Aranjuez, 9 de marzo de 1797 y contestación de este último al primero, Aranjuez, 11 de marzo de 1797. AHN, Estado, Leg. 4437. Carta de Charles Delacroix a François Pérignon, París, 17 de abril de 1797.

26. AHN, Estado, Leg. 3946. Carta de Francisco Cabarrús a Bernardo del Campo, París, 16 de junio de 1797. LA PARRA LóPEZ, 1992: 130. 
mano de Francisco Cabarrús, quien negociaría secretamente para reivindicar los intereses españoles ${ }^{27}$.

Las propuestas españolas eran sencillas y se centraban en las pretensiones primordiales de los monarcas. Se exigía a Inglaterra la devolución de Gibraltar y Nootka, además del derecho de pesca en Terranova. Si Francia conseguía esto, España estaría dispuesta a ceder la Luisiana y la Florida a cambio de que al duque de Parma se le diesen Córcega y Cerdeña, aunque se establecía que si se podía conseguir Gibraltar sin el sacrificio de las posesiones americanas sería mucho mejor. Sin embargo, esta línea que el gobierno español quería llevar con respecto al hermano de la reina María Luisa, se iba a encontrar con la oposición férrea de éste al abandono de sus territorios patrimoniales y la negativa de los franceses a conceder las islas italianas, pues sólo querían compensarle con la Romaña ${ }^{28}$.

Las pretensiones parmesanas eran mucho más sencillas, Fernando no quería perder ninguno de los súbditos que tenía, que se respetasen sus límites fronterizos y que se le diese el territorio que separaba Parma de Guastalla ${ }^{29}$. No obstante, las nuevas peticiones del infante serían muy difíciles de alcanzar, puesto que en este momento la comunicación entre los dos gobiernos aliados no era buena. El príncipe de la Paz se quejaba en nombre del rey de la

27. AHN, Estado, Leg. 3946. Carta de Francisco Cabarrús a Bernardo del Campo, París, 16 de junio de 1797 y carta de Bernardo del Campo y Francisco Cabarrús, París, 18 de junio de 1797. AHN, Estado, Leg. 6670. Carta de Manuel Godoy a François Pérignon, Aranjuez, 22 de junio de 1797. ANF, serie AF/III, vol. 57, negociación de Lille, 1797. LA PARRA LÓPEZ, 1992: 130.

28. AHN, Estado, Leg. 3946. Contestación de Manuel Godoy a las cartas de Francisco Cabarrús y Bernardo del Campo, Aranjuez, 28 de junio de 1797 y cartas de Francisco Cabarrús a Manuel Godoy, París, 8 y 20 de julio de 1797. AHN, Estado, Leg. 6670. Carta de François Pérignon a Manuel Godoy, Aranjuez, 18 de julio de 1797 y carta de Manuel Godoy a François Pérignon, Madrid, 19 de julio de 1797. Berte-Langereau, 1958: 44-45. LA PARRA LÓPEZ, 1992: 48-49,132.

29. AMAE, Correspondance politique Parme, vol. 46. Carta de Bernardo del Campo a Charles Delacroix, París, 14 de agosto de 1797. AHN, Estado, Leg. 6670. Carta de Manuel Godoy a Bernardo del Campo, San Ildefonso, 15 de agosto de 1797. BERTE-LANGEREAU, 1958: 41-42. 
reserva con la que actuaba el Directorio con respecto a su aliada, que tantos esfuerzos había realizado ${ }^{30}$.

Realmente, tanto el ministro español como los monarcas tenían muy claro que no se resignarían a entregar territorios tan valiosos en América por una pequeña cesión en tierras italianas. Simplemente, la diplomacia francesa utilizaba la cuestión de Parma para presionar a su aliada en un intento por obtener mayores concesiones de ella pues, como hemos adelantado anteriormente, al Directorio le interesaba lograr ciertos enclaves en el continente americano. Una presión que se acentuará con la llegada al poder de Napoleón Bonaparte. Finalmente, tras el cierre del congreso de Lille sin conseguir la paz y, por otro lado, la firma del Tratado de Campo Formio, por el que se reconocían las nuevas repúblicas hermanas, Cisalpina y Ligur, las negociaciones para el engrandecimiento del ducado quedaron estancadas ${ }^{31}$.

En el mes de noviembre las tan temidas pesadillas del duque de Parma se hacían realidad y los ejércitos cisalpinos ocupaban los dominios que se encontraban en la margen izquierda del río Po, lo que era un total incumplimiento del tratado de paz que había firmado casi un año antes con el gobierno francés. La primera reacción de Fernando fue pedir la mediación del embajador de España en Parma, el conde de Valparaíso, el cual se negó porque creía que no era válida para este caso por tratarse de la República Cisalpina y no de Francia. Con el paso de los días la situación de angustia del hermano de la reina crecía ante las noticias que recibía sobre las miras hostiles de los cisalpinos contra Plasencia y la recomendación de Valparaíso de abandonar sus dominios para evitar la inseguridad en la que vivía siendo vecino del nuevo Estado republicano. Finalmente, el duque decidiría salir de sus posesiones ${ }^{32}$.

Tras la negativa del conde de Valparaíso a inmiscuirse en el problema con los cisalpinos, Fernando decidía recurrir a Godoy para arreglar su situación. En primer lugar, demandaba la destitución de este plenipotenciario, puesto

30. AHN, Estado, Leg. 6670. Carta de Manuel Godoy a François Pérignon, Madrid, 19 de julio de 1797.

31. AHN, Estado, Leg. 6670. Carta de Manuel Godoy a Bernardo del Campo, San Ildefonso, 18 de septiembre de 1797. GUYOT, 1977: 429-430. BERTE-LANGEREAU, 1958: 47-48.

32. AHN, Estado, Leg. 6670. Carta de Bernardo del Campo a Manuel Godoy, París, 7 de agosto de 1797. AHN, Estado, Leg. 4375. Carta del conde de Valparaíso a Manuel Godoy, Parma, 16 de noviembre de 1797. BerTE-LANGEREAU, 1958: 47-49. 
que no le había sentado nada bien su negativa a viajar a Milán y dialogar con los directores cisalpinos, de la misma forma que no le gustó la proposición de prescindir de sus dominios. En segundo lugar, pedía al secretario de Estado que la diplomacia española actuase en París para luchar por sus intereses y que instara a José de la Huerta, embajador español en Génova, para acudir a Milán a entrevistarse con sus mandatarios y llegar a un acuerdo en el que se respetasen los derechos parmesanos. Antes de que el príncipe de la Paz contestase a estas ofertas, el gobierno ducal abrió otra vía para defenderlos sin contar con la ayuda de Carlos IV. El infante requería al general Bonaparte que se convirtiese en el mediador entre él y la república vecina, en un intento por lograr una compensación por las conquistas arrebatadas. Sin embargo, la mediación no sería gratuita, pues debía firmar un empréstito de ocho millones de reales a la armada francesa ${ }^{33}$. Esta petición, junto con la invasión, era el precio que el pequeño ducado y España debían pagar por no haber aceptado, el primero, el canje de los territorios y la segunda, la concesión de la Luisiana y la Florida.

En diciembre, el príncipe de la Paz comunicaba su decisión de enviar a José de la Huerta a la capital parmesana y anunciaba la movilización del embajador Campo, que presto se pondría a trabajar en los oficios a favor de Parma en un intento por lograr la salida de las huestes cisalpinas y la garantía del Directorio de los territorios del infante de Parma. Mientras tanto, los problemas no dejaban de crecer en la corte ducal. La propaganda revolucionaria esparcida por las tropas que habían ido penetrando empezaba a convertirse en algo que temer, así como la utilización de algunos hospitales para el ejército francés a costa del gabinete parmesano y la instalación de unos doce mil hombres franceses al mando del general Massena, actos que no hicieron más que agravar la mala situación económica del pequeño ducado ${ }^{34}$.

33. AHN, Estado, Leg. 4375. Carta del conde de Valparaíso a Manuel Godoy, Parma, 16 de noviembre de 1797. AHN, Estado, Leg. 4451. Carta del duque de Parma a Bernardo del Campo, Colorno, 24 de noviembre de 1797, carta de Bernardo del Campo a Manuel Godoy, París, 5 de diciembre de 1797 y carta de Manuel Godoy a Bernardo del Campo, Madrid, 14 de diciembre de 1797. BERTE-LANGEREAU, 1958: 50-55.

34. AHN, Estado, Leg. 4451. Carta de Manuel Godoy a Bernardo del Campo, Madrid, 10 y 14 de diciembre de 1797 y carta de Manuel Godoy a José de la Huerta, San Lorenzo, 9 de diciembre de 1797. BERTE-LANGEREAU, 1958: 56-58. 
Con la llegada del año 1798, las cuestiones diplomáticas en torno a Parma se centraban en conseguir la recuperación de los terrenos usurpados al duque, en la adquisición del territorio que permitiría unir Guastalla con Parma o, en su caso, obtener una indemnización. Una cesión que estaba prevista que se tratara en Milán junto con Bonaparte y José de la Huerta, pero el general dejó el tema a un lado para centrase en la lucha en el Mediterráneo y Egipto. La negociación se trasladaría a la ciudad gala, de nuevo bajo mediación española. El infante, en un primer momento, pensó enviar a la capital francesa al abogado Luis Bolla, que ya había tratado el acuerdo de paz entre la república y el ducado, aunque en última instancia decidió instruir al recién nombrado embajador de España en París, José Nicolás de Azara, para luchar por sus intereses ${ }^{35}$.

En suma, a Azara se le encargó intentar alcanzar un arreglo de límites con la República Cisalpina que redundase en el aumento de sus dominios a modo de compensación o, en su defecto, lograr una buena colocación para el duque de Parma en otro lugar de la península italiana. Al poco tiempo del comienzo de las negociaciones empezó a coger más fuerza esta segunda opción; se planteó la República de Luca, pero el Directorio se mostraba entonces muy reticente a complacer a España. Las cuestiones de la fallida paz franco-portuguesa y los problemas que, desde inicios de 1798, tuvieron lugar en la embajada francesa en Madrid, a lo que se le añade el abandono de Godoy de la secretaría de Estado, no ayudaban a las pretensiones españolas en torno a Parma. Estaba claro que las propuestas vagas por parte del Directorio y el arreglo de los límites no era más que una estrategia para entretener tanto al gobierno español como al parmesano, mientras se les dejaba fuera de la reorganización de los Estados italianos ${ }^{36}$.

35. AHN, Estado, Leg. 4369. Cartas de José de la Huerta a Manuel Godoy, Parma, 11 y 30 de enero, 15 de febrero, 15 y 30 de marzo de 1798. AHN, Estado, Leg. 6686. Carta de Francisco Cabarrús a Manuel Godoy, París, 6 de febrero de 1798. AHN, Estado, Leg. 3974. Carta de Manuel Godoy a José Nicolás de Azara, Aranjuez, 19 de abril de 1798. BERTE-LANGEREAU, 1958: 58-59.

36. AHN, Estado, Leg. 4561. Carta de Manuel Godoy a Bernardo del Campo, Aranjuez, 15 de enero de 1798. AHN, Estado, Leg. 3943. Carta de Francisco Cabarrús a Manuel Godoy, París, 16 de enero de 1798. AHN, Estado, Leg. 6686. Carta de Manuel Godoy a José Nicolás de Azara, San Ildefonso, 26 de febrero de 1798. AHN, Estado, Leg. 4018. Cartas de José Nicolás de Azara a Francisco Saavedra, París, 27 de mayo y 18 


\section{Nueva vía diplomática y tratado de engrandecimiento}

Tras numerosos intentos fallidos, a finales de 1798, el infante intentaría una vía diplomática propia sin contar con el gabinete madrileño. Su idea consistía en tratar de manera directa con los cisalpinos para promover la restitución del Ultra Po, no teniendo en cuenta la misión que se le había encargado al ministro español en Parma. Esta situación provocaría la entrada en el teatro político, de forma más activa de lo que lo había hecho anteriormente, de la reina María Luisa $^{37}$. Es de sobra conocido el deseo de la monarca por ver engrandecida su casa de origen y que de este anhelo era también partícipe Carlos IV. Por ello, de ahora en adelante será ella la que sucesivamente expondrá a su hermano los pasos a seguir en sus relaciones con Francia:

Me dices que cuide de tus cosas. Ya has visto como lo he hecho desde el principio de la resolución de Francia y puedes calcular cuánto se habrá interesado el rey por ti con la Francia, cuando habiendo sufrido tanto todos los Estados de Italia sólo tú has quedado libre, pero es necesario por lo mismo que en todo te comportes con la dignidad y decoro que te corresponde por tu nacimiento y por nosotros, consultando los pasos que pienses dar con el ministro Huerta [...]. Sigue los que él te aconseje que está instruido por nuestro embajador Azara de lo que te conviene y de cuanto obramos por ti y no errarás, ni te expondrás a que los pasos, que nosotros hagamos con el mayor acierto, se pierdan por querer prestar confianza a medias. Vive seguro de que tú sólo eres la única persona por quien nosotros tenemos interés en Italia y que interpondremos siempre los vínculos de nuestra amistad y alianza con el gobierno francés por tu sólida existencia y mayor aumento de tus Estados ${ }^{38}$.

de junio de 1798. AHN, Estado, Leg. 6675. Carta de Francisco Saavedra a José Nicolás de Azara, Aranjuez, 19 de abril de 1798. AMAE, Correspondance politique Parme, vol. 46. Relación enviada al Directorio Ejecutivo: De l'Italie en général et particulierment de l'échange du Duché de Parme contre l'isle de Sardaigne, s.l, pluvioso año VI (21 de enero-18 de febrero de 1798). FugIER, 2008: 102. BERTE-LANGEREAU, 1958: 59-60. Chinchilla Galarzo, (2019): 239-262.

37. AHN, Estado, Leg. 4369. Carta de José de la Huerta a Francisco Saavedra, Parma, 30 de octubre de 1798 y carta del conde Ventura a José de la Huerta, Parma, 23 de octubre de 1798. AMAE, Correspondance politique Parme, vol. 46. Memoria de José Nicolás de Azara a Charles Maurice de Talleyrand, París, 24 de noviembre de 1798. LA PARRA LÓPEZ, 1992: 87; 2005: 143. FUGIER, 2008: 102-103.

38. AHN, Estado, Leg. 4369. Copia de una carta de la reina María Luisa al duque de Parma, transcrita para José de la Huerta, Madrid, 30 de noviembre de 1798. 
A pesar de las amenazas veladas de su hermana, el duque no quiso utilizar la mediación española para tratar los asuntos con Milán. La negociación se seguía totalmente en secreto entre el ministro cisalpino Berri y el abogado Luis Bolla ${ }^{39}$.

Después de la formación de la segunda coalición antirrevolucionaria, el fracaso de las conversaciones de Rastadt y las sucesivas presiones del gabinete francés a su homólogo español para que incrementara la ayuda militar, se abría un periodo difícil en las relaciones hispano-francesas. La monarquía española tenía que centrarse en la única vía posible, la de acercarse al gobierno revolucionario para conservar su integridad, por lo que se tuvo que aplazar el deseo de los monarcas españoles de engrandecer los dominios ducales ${ }^{40}$. Sin embargo, con el reinicio de la guerra entre Francia y las potencias coaligadas en la primavera de 1799, el duque quedaba a merced de los austriacos. Este hecho convenció a Carlos IV de la imposibilidad de mantener a Fernando de Parma en sus Estados y reiteró al Directorio que garantizara la neutralidad del ducado, pero las campañas militares paralizaron las negociaciones sobre la cesión del Ultra Po y en junio el infante se veía obligado a abandonar sus posesiones $^{41}$.

Con la llegada al poder de Napoleón Bonaparte a finales de 1799, el plan en relación al ducado se modificó. La aspiración del general se centraba en engrandecer la República Cisalpina a costa de los Estados parmesanos y debido a ello, decidió reactivar el proyecto de canje de los mismos. Se ponían sobre la mesa nuevas aspiraciones. Bonaparte pretendía fidelizar de alguna manera a los monarcas españoles para que estos participasen en sus proyectos bélicos y diplomáticos, proporcionando el tan deseado acrecentamiento. La negociación acerca de Parma sería el medio que el Consulado francés utilizaría para consolidar la alianza entre Francia y España, como veremos posteriormente. Los territorios del duque entorpecían las miras del nuevo gobernante francés porque se encontraban entre las Repúblicas Cisalpina y Ligur. Además,

39. AHN, Estado, Leg. 4369. Cartas de José de la Huerta a Mariano Luis de Urquijo, Parma, 15 de noviembre, 30 de diciembre de 1798 y 15 de diciembre de 1799.

40. LA PARRA LÓPEZ, 2005: 224; 1992: 87. FugIER, 2008: 81-82.

41. AHN, Estado, Leg. 3999. Carta de Mariano Luis de Urquijo a José Nicolás de Azara, Madrid, 16 de abril de 1799, carta de José Nicolás de Azara a Mariano Luis de Urquijo, París, 5 de julio de 1799. BERTE-LANGEREAU, 1958: 64-85. 
existía una cuestión heredada de tiempo del Directorio: el precio a pagar por parte de la corte madrileña si se producía el aumento sería la Luisiana. Tras la pérdida de Egipto, el Primer Cónsul quería una compensación en el continente americano para sus operaciones con respecto a Santo Domingo y disponer así de un punto básico de apoyo para la eventual guerra marítima con Inglaterra. Asimismo, en el momento en que llegasen las negociaciones de paz con dicha potencia, contaría con una moneda de cambio que el anterior gobierno galo no había podido obtener ${ }^{42}$.

El único de los actores que no estaba demasiado de acuerdo con los deseos de sus cuñados y del cónsul era Fernando, quien aspiraba a desligarse del dominio galo, aunque su hermana procuró reconducir sus propósitos:

tú hermano mío, serás feliz si sigues la nuestra (se refiera a la conducta). Sabes que debes a la influencia del rey y a su respeto en Francia, el haberte conservado en tus Estados, siendo el único potentado de Italia que lo ha logrado $[\ldots]$ y si esto ha sucedido en medio de tempestades, de revoluciones, ¿qué no puedes esperar ahora en que las cosas van más consolidadas y con otro sistema? Es necesario que te portes con el miramiento, que es tan propio de tu prudencia, manteniéndote neutral [...] ni por ningún motivo debes abandonar, como lo hiciste antes, exponiéndote a perderlo todo $[\ldots]^{43}$.

Estaba claro que las recomendaciones de su hermana le instaban a no aliarse con los austriacos, manteniendo la neutralidad hasta que la paz permitiese el engrandecimiento.

A principios del año 1800, el proyecto sobre la reubicación de los territorios ducales aparentaba hacerse efectivo. El período de buenas relaciones entre los monarcas españoles y el Primer Cónsul empezaba a dar sus frutos. Urquijo, nuevo secretario de Estado español, abría una nueva vía para tratar la ampliación del pequeño ducado con el embajador francés en España. Realmente las nuevas conversaciones comenzaron no sin problemas en París. Las propuestas llegaban a corte madrileña de mano de Talleyrand, quien aprovechó que Bonaparte estaba en el frente para adelantar la negociación a través de entrevistas extraoficiales con el banquero español Hervás. La condición sería

42. LA PARra LÓPez, 2005: 226-227. FugIER, 2008: 103-104.

43. AHN, Estado, Leg. 4440. Copia de un párrafo de una carta escrita por la reina María Luisa de Parma a su hermano, el infante duque de Parma, s.l., 30 de noviembre de 1799. 
la concesión de la Luisana a cambio del aumento de los dominios parmesanos en otro lugar de Italia, algo que a Urquijo no parecía molestarle, pero ya en las primeras tomas de contacto entrarían en juego las intrigas ${ }^{44}$ :

Al día siguiente de esta conversación, vino S[imón, secretario de Talleyrand] a encargarme de expedir al instante y asegurar que estaba T [alleyrand] muy en nuestro favor. Como S[imón] es el hombre de T[alleyrand], no dudé hablarle de intereses y llegamos hasta preguntarle el cuánto sería necesario aquí para hacer frente a las gratificaciones, etc y me pidió tiempo para pensarlo. Al día siguiente me dijo que esto debía quedar al juicio de Vm. en proporción del servicio que se exigiese suponiendo que no había visto $\mathrm{T}$ [alleyrand] para darme esta respuesta, y encargándome, que no hablase de intereses en el mismo correo que hablase del asunto de Parma para que la oferta de servicios sea más noble y que convendría que cuanto instruyese a Vm. de esto que fuese en cifra, y me repitió muchas veces que nadie de aquí, ni Cambacérès, ni otro alguno debía saber nada, porque lo que se hiciese sería entre Bonaparte y T[alleyrand] sin intervención alguna de más personas ${ }^{45}$.

En estos primeros contactos se hablaba de que la negociación debía ser ignorada por el embajador francés, Alquier y su homólogo español, Múzquiz. El planteamiento a discutir sería la posible concesión del título de rey para el duque, que no tendría efecto hasta la paz general, y en las conversaciones solo intervendrían Bonaparte, Talleyrand y el banquero Hervás en París. Pronto, el dinero y la corrupción comenzarían a ser el hilo conductor de las mismas ${ }^{46}$ :

Confieso de buena fe que, aunque sé mucho de corrupción de mundo, no deja de sorprenderme la excesiva que veo, pero como es menester jugar con las cartas que haya, diré a Vm. que si S.A.R. el señor infante duque le dejan sus Estados y los del Ultra Po de la disputa que le pertenece, nada tenemos que dar, pues entonces nada adelanta y queda como estaba. Si le dan las Legaciones con Módena y Reggio, no habría inconveniente en ofrecerles de

44. AHN, Estado, Leg. 6697. Carta de Mariano Luis de Urquijo a José Martínez de Hervás, Aranjuez, 22 de junio de 1800 y carta de Charles Maurice de Talleyrand a Ignacio Múzquiz, París, 7 de floreal año VIII (27 de abril de 1800). Fugier, 2008: 104-106. BERTE-LANGEREAU, 1958: 95-98.

45. AHN, Estado, Leg. 3963. Carta reservada de José Martínez Hervás a Mariano Luis de Urquijo, París, 11 de junio de 1800.

46. AHN, Estado, Leg. 3963. Carta reservada de José Martínez Hervás a Mariano Luis de Urquijo, París, 11 de junio de 1800 y contestación de este último, Aranjuez, 22 de junio de 1800. FUGIER, 2008: 105-106. 
dos a tres millones de duros y si le dejasen el Milanesado, la misma cosa, se entiende todo quedándose con sus Estados de Parma, Plasencia y Guastalla. En proporción de esta cantidad puede Vm. ir haciendo sus ofertas según lo que le dejen, pues ni se puede fijar hasta ver los progresos rápidos de sus ejércitos, y si dominan enteramente la Italia $[\ldots]^{47}$.

La estrategia española consistía en esperar a la paz general para pagar el dinero que el gabinete francés le demandaba y procurar que los territorios cedidos al duque de Parma fuesen reconocidos en dicha paz. Igualmente, los monarcas querían asegurarse que las propuestas de engrandecimiento de Talleyrand fuesen firmes para no anticiparse al pago, como había ocurrido anteriormente en la mediación para la paz franco-portuguesa ${ }^{48}$ :

No sólo se podrían dar los tres millones encima a B[onaparte] y T[alleyrand] sino también la Luisiana y muchísimas gracias, sobre todo, pudiéndonos lisonjear de que paz semejante nunca se habría logrado, pero esto se debe entender a la paz general, pues sino los americanos que conocen la importancia de que esté la Luisiana en nuestro poder impedirían la cesión y entrega, $[\ldots]^{49}$.

La Luisiana era el gran botín que tanto Talleyrand como Bonaparte ambicionaban, aparte de algo de liquidez para su erario. Por consiguiente, pocos días después de estos primeros contactos en París, el gobierno francés decidía enviar a España al general Berthier, pese a que en Madrid ya residía el embajador Alquier. Detrás del envío de este sujeto se encontraban el ansia del Primer Cónsul por resolver ciertos escollos de la alianza hispano-francesa. Uno de sus ases sería sin duda utilizar el afán de Carlos IV y María Luisa por alcanzar sus intereses parmesanos en favor de la reorganización de los Estados italianos que pretendía Bonaparte ${ }^{50}$.

47. AHN, Estado, Leg. 3963. Carta de Mariano Luis de Urquijo a José Martínez Hervás, Aranjuez, 22 de junio de 1800.

48. AHN, Estado, Leg. 3963. Carta de Mariano Luis de Urquijo a José Martínez Hervás, Aranjuez, 22 de junio de 1800. FugIER, 2008: 105-106. BERTE-LANGEREAU, 1958: 93-94. Chinchilla Galarzo, (2019): 239-262.

49. AHN, Estado, Leg. 3963. Carta de Mariano Luis de Urquijo a Ignacio Múzquiz, Aranjuez, 22 de junio de 1800.

50. AHN, Estado, Leg. 3963. Carta de Ignacio Múzquiz a Mariano Luis de Urquijo, París, 7 de agosto de 1800. AHN, Estado, Leg. 4456. Carta de Nicolás Blazco Orozco, ministro plenipotenciario interino en el ducado de Parma, a Mariano Luis de Urquijo, 
Las instrucciones de Berthier eran muy claras: a cambio del engrandecimiento de Parma, España tendría que entregar la Luisiana y proporcionar diez buques de guerra, a lo que se sumaba alguna labor de espionaje militar y la confluencia del gobierno español en el ataque a Portugal que proyectaba el Primer Cónsul. Por fin, el deseo de la reina María Luisa estaba más cerca de cumplirse, pues las negociaciones fueron mucho más rápidas de lo que todos habían pensado en un principio. El primero de octubre de 1800 se firmaba el conocido como tercer Tratado de San Ildefonso, por el que el duque recibiría un Estado de iguales súbditos ya fuese en la Toscana, las legaciones pontificias u otro lugar en la península itálica. Por otro lado, Carlos IV se comprometía a ceder a Francia seis barcos de guerra y la Luisiana ${ }^{51}$.

Un acuerdo que no sería igualitario y que no haría más que convertir a Fernando de Parma en rehén de la política napoleónica a partir de este momento. No obstante, la rúbrica de este convenio respondía a la decisión de los monarcas españoles de centrar sus intereses en el territorio italiano para favorecer a su hija, dando menos importancia a la cesión de una pequeña parte del imperio ultramarino. En otro orden de cosas, debemos destacar que el apartado relativo a los regalos oficiales fue muy cuantioso ${ }^{52}$, aunque nada comparable a lo que se destinó en sobornos secretos. El gobierno español gastó seis millones de libras en ganarse a los distintos miembros del gabinete francés. Tres millones debían entregarse a la ratificación del tratado y los restantes cuando el duque estuviese asentado en sus nuevos dominios. A

Florencia, 29 de julio de 1800. AHN, Estado, Leg. 6697. Carta de Mariano Luis de Urquijo a Ignacio Múzquiz, San Ildefonso, 2 de octubre de 1800. BeRTE-LANGEREAU, 1958: 92-102. FUGIER, 2008: 106-107.

51. A la buena acogida de este nuevo enviado ayudaría el envío de Bonaparte a Carlos IV de una de las tres medallas de platino, que el Primer Cónsul había mandado grabar en conmemoración del 14 de julio y la noticia de su victoria en la batalla de Marengo. FUGIER, 1967: 901; 2008: 107-108. LA PARRA LÓPEZ, 2003: 230. BERTE-LANGEREAU, 1958: 101-102.

52. Carlos IV dio al general Berthier su retrato adornado con diamantes y dos caballos; a Talleyrand se le mandó un servicio de mesa en plata; Hauterive (que hacía las funciones de secretario de legación para Berthier) recibió 300 luises; a Josefina Bonaparte se le enviaron unos diamantes, con un precio de 100.000 libras y la amante de Talleyrand también recibió un solitario por valor de 20.250 libras. A Urquijo el ministro de Asuntos Exteriores francés le regaló unos tapices de los Gobelinos. FUGIER, 2008: 108-109. 
finales de ese mismo año, el banquero Hervás ya había proporcionado más de dos millones de libras, de las que sabemos con certeza que quinientas mil fueron para Berthier y alrededor de doscientas cincuenta mil lo fueron para Talleyrand. Al comenzar 1801, el ministro de Asuntos Exteriores galo pidió que el resto del montante fuese abonado por la corte madrileña, pero la falta de efectivo de la Hacienda provocó un retraso. Meses después, Azara, de nuevo embajador en París, cortó las partidas de dinero destinadas al pago del engrandecimiento, pues este no se había efectuado aún ${ }^{53}$.

Por otra parte, se abría un nuevo escollo, ya que el Tratado de San Ildefonso solo recogía la aceptación del gobierno español, pero no la del señor de los dominios ducales. Consecuentemente, Bonaparte centró su estrategia en conseguir el beneplácito del infante parmesano y alguna concesión más de los monarcas españoles. Sin embargo, Fernando se resistía a abandonar sus Estados y María Luisa tendría que volver a mediar en una cuestión a la que tanto el Primer Cónsul, como los reyes querían poner fin. Para ello, Napoleón destituyó a Alquier como embajador en Madrid y nombró a alguien más cercano, su hermano Luciano, para presionar al príncipe de la Paz. A principios de 1801, la ambición del cónsul francés por reorganizar Italia se alcanzaba con la entrada de Murat en la Toscana y la firma de la paz de Lunéville, donde se estipulaba que dicho territorio quedaba libre para crear el nuevo reino de Etruria, convirtiendo al duque en rey, pero no en su persona, sino en la de su hijo ${ }^{54}$. Un plan que el general llevaba urdiendo algunos meses y que los soberanos se vieron obligados a aceptar porque se dieron cuenta de que el recién creado reino no sobreviviría y tampoco mantendrían su influencia en Italia, si no se seguían los dictados napoleónicos ${ }^{55}$.

53. AHN, Estado, Leg. 3963. Carta de Ignacio Múzquiz a Mariano Luis de Urquijo, París, 10 de diciembre de 1800. AHN, Estado, Leg. 6694. Carta de Ignacio Múzquiz a Mariano Luis de Urquijo, París, 10 de diciembre de 1800. AHN, Estado, Leg. 5205. Carta reservada de Pedro Cevallos a Miguel Cayetano Soler, ministro de Hacienda, Aranjuez, 17 de febrero de 1801. FugIER, 2008: 108-109.

54. A este reconocimiento del territorio toscano en el tratado de paz entre el emperador y Francia, contribuyeron las arcas españolas con 300.000 libras. Esta partida de dinero fue entregada al conde de La Forest, ayudante de José Bonaparte en las negociaciones de Lunéville.

55. AHN, Estado, Leg. 2821. Carta de Manuel Godoy a María Luisa de Parma, s.l./s.f. (circa 1800). AHN, Estado, Leg. 6700. Cartas de Ignacio Múzquiz a Pedro Cevallos, París, 14 
Con respecto a lo estipulado en el Tratado de San Ildefonso, el acuerdo de Lunéville representaba una pérdida de población y además no contemplaba explícitamente la conversión del ducado en reino, pero finalmente se firmó la Convención de Aranjuez el 21 de marzo de 1801, con la renuncia de Fernando a su título y tierras, algo tremendamente doloroso para su hermana la reina, ya que veía a su hermano desposeído de todo mientras que el infante Luis se convertía en rey de Toscana. Por su parte, Napoleón obtenía la Luisiana y la isla de Elba, adquiría los dominios parmesanos para aumentar los de la República Cisalpina y Ligur y asimismo ganaba un aliado que podría ser considerado un Estado vasallo en el centro de Italia ${ }^{56}$.

\section{Conclusiones}

El interés y la preocupación de los monarcas y en especial de la reina por el ducado de Parma provocó, entre otros motivos, que el gobierno español se viese obligado a firmar una alianza con la potencia que se estaba adueñando de la península italiana para, precisamente, reactivar los anhelos de influencia sobre dicho territorio. Así se volvía a la dinámica de los Pactos de Familia, a la unión con Francia, pero no porque les enlazase un vínculo de parentela, pues los Borbones franceses habían desaparecido, sino porque España necesitaba de la ayuda del poderoso poder militar de la nueva república para llevar a cabo sus pretensiones políticas.

En cuanto a las relaciones diplomáticas con la corte ducal, tenemos que destacar el papel relevante de la reina que, salvaguardando la lealtad a su casa de origen, llegó a tener una función mayor que la de su marido en la dirección

y 30 de enero, 3, 7 y 23 de febrero de 1801. AHN, Estado, Leg. 5205. Carta de Ignacio Múzquiz a Pedro Cevallos, París, 8, 13 y 16 de febrero de 1801. FUGIER, 1967: 903-904, 910-911; 2008: 110-111, 122-123. CORONA BARATECH, 1948: 49-50. GIMÉNEZ LÓPEZ, 1994: 78-88. BERTE-LANGEREAU, 1958: 104-108. RAO, 2003b: 596-598.

56. AMAE, Correspondance politique Parme, vol. 47. AHN, Estado, Leg. 5205. Carta de Pedro Cevallos a Ignacio Múzquiz, Aranjuez, 26 de febrero y 2 de marzo de 1801 y carta de Ignacio Múzquiz a Pedro Cevallos, París, 23 de febrero de 1801. AHN, Estado, Leg. 6702. Cartas de Pedro Cevallos a José Nicolás de Azara, Aranjuez, 12 y 19 de marzo de 1801. AHN, Estado, Leg. 3422. Carta de José Nicolás de Azara a Pedro Cevallos, París, 26 de marzo de 1801. AHN, Estado, Leg. 6701. Carta de Pedro Cevallos a José Nicolás de Azara, 6 de abril de 1801. FugIER,1967: 911-912; 2008: 123-125. LA PARRA LÓPEZ, 2005: 291-293. EGIDO LÓPEZ, 2001: 170-171. BERTE-LANGEREAU, 1958: 111-118. 
de la política con respecto a su territorio natal. Del mismo modo, hemos podido observar que el poder de María Luisa fue muy amplio, pero siempre supeditado al juicio y a la autoridad de Carlos IV y no a los de Manuel Godoy. Los monarcas formaron un equipo que intentó luchar en pos de mantener los intereses dinásticos; dictaminaban y comunicaban de manera conjunta sus decisiones, siendo la reina un instrumento más de la diplomacia que el rey utilizó para conseguir sus máximas.

Desde 1796, el engrandecimiento de Parma estaba en el punto de mira del Directorio francés, junto a sus pretensiones en el continente americano y el deseo de lograr una mayor implicación de España en la alianza. Unas aspiraciones que no consideramos propias de los gobiernos de Bonaparte, sino que para nosotros son anteriores en el tiempo. Podemos afirmar que el Primer Cónsul adoptó la idea del Directorio de obtener la Luisiana a cambio del acrecentamiento del ducado, territorio estratégico para su flota marítima y sus proyectos de expansión colonial en América. Y serían sus presiones las que finalmente consiguieron dicho objetivo, al igual que la tan deseada ayuda naval española que había sido un escollo en las relaciones hispano-francesas a lo largo de los años finales de la centuria.

Por último, no podemos olvidar que la alianza con España le permitió llevar a cabo su política expansionista en Italia. Napoleón consiguió, con la firma del Convenio de Aranjuez, reforzar sus posesiones en el norte, como barrera frente a los ataques de sus enemigos y, mediante la creación ex profeso del reino de Etruria, un Estado vasallo en el centro de Italia que le debía todo a él. La instauración de un trono real reflejaba la toma de conciencia de su propio poder, pues se sentía capaz de instituir y legitimar cortes reales. Un proceso que se inicia aquí y que dará lugar, en el periodo imperial, a la aparición de un nuevo mapa europeo compuesto por nuevas casas reales y ducales en las que Bonaparte impondrá a personas de su sangre y su entera confianza, siendo la pequeña monarquía de Etruria el proyecto primigenio.

\section{Bibliografía}

Álvarez-Coca GonZÁlez, María J., «La Toscana en el Archivo Histórico Nacional (Madrid). Fuentes para su estudio», en Marcella Aglietti (ed.), Le relazioni tra Spagna e Toscana per una storia mediterranea dell'Ordine dei Cavalieri di Santo 
Stefano: Atti del Convegno Internazionale di Studi: Istituzioni, potere e società, Pisa, 18 mayo 2007, Pisa, Edizioni ETS, 2007: 435-485.

Álvarez-Coca GonzÁlez, María J., «María Luisa de Borbón (1782-1824), de reina de Etruria a duquesa de Lucca. Su documentación en el Archivo Histórico Nacional (Madrid)», en Marco Manfredi (ed.), Spagnoli a Palazzo Pitti: il Regno d'Etruria (1801-1807): Atti del convegno internazionale di studi, Florencia-Pisa, 29 noviembre-1 diciembre 2007, Florencia, Consiglio regionale della Toscana/Università di Pisa/Gabinetto G.P., Vieusseux, 2013: 437-477.

BÉCKER, Jerónimo, Historia de las relaciones exteriores de España durante el siglo XIX. Apuntes para una historia diplomática, vol. I, Pamplona, Analecta, 2006. BERTE-LANGEREAU, Jack, La política italiana de España bajo el reinado de Carlos IV, Madrid, Revista de Occidente, 1958.

Calvo Maturana, Antonio, María Luisa de Parma: Reina de España, esclava del mito, Granada, Universidad de Granada, 2007.

Chinchilla Galarzo, Ainoa, «El Tratado de San Ildefonso de 1796: ¿pragmatismo político, error de Godoy o Pacto de Familia pero sin Familia?», en María Ángeles Pérez Samper y José Luis Betrán Moya (eds.), Nuevas perspectivas de investigación en Historia Moderna: Economía, Sociedad, Política y Cultura en el Mundo Hispánico, Madrid, Fundación Española de Historia Moderna, 2018: 680-690. Disponible en: http://hdl.handle.net/10261/173502 [consultado el 10 de diciembre de 2018].

Chinchilla Galarzo, Ainoa, «Portugal y la fallida paz con Francia: mediación española y corrupción francesa (1796-1800)», Espacio, tiempo y forma. Serie IV Historia Moderna, 32 (2019): 239-262. Disponible en: http://revistas.uned. es/index.php/ETFIV/article/view/22893 [consultado el 15 de agosto de 2019]. Corona Baratech, Carlos E., José Nicolás de Azara. Un embajador español en Roma, Zaragoza, Institución «Fernando el Católico», 1948.

EGIDO LÓPEZ, Teófanes, Carlos IV, Madrid, Arlanza Ediciones, 2001.

ESPADAS Burgos, Manuel, «La Spagna di Carlo IV e il Regno d'Etruria. Rapporti e protagonisti» en Marco Manfredi (ed.), Spagnoli a Palazzo Pitti il Regno d'Etruria (1801-1807): Atti del convegno internazionale di studi, Florencia-Pisa, 29 novembre-1 dicembre 2007, Florencia, Consiglio regionale della Toscana/ Università di Pisa/Gabinetto G.P., Vieusseux, 2013: 61-70. 
FugIER, André, «La Revolución Francesa y el Imperio Napoleónico», en Pierre Renouvin (dir.), Historia de las Relaciones Internacionales, t. I, vol.2, Madrid, Aguilar, 1967.

FugIER, André, Napoleón y España (1799/1808), Madrid, Sociedad Estatal de Conmemoraciones Culturales/Centro de Estudios Políticos y Constitucionales, 2008.

Giménez López, Enrique, El fin del Antiguo Régimen. El reinado de Carlos IV, Madrid, Historia 16/Temas de hoy, 1996.

GuYOT, Raymond, Le Directoire et la paix de l'Europe des traités de Bâle a la deuxième coalition (1795-1799), Ginebra, Slatkine Megariotis Reprints, 1977. Disponible en: https://gallica.bnf.fr/ark:/12148/bpt6k72831.texteImage [consultado 12 de septiembre de 2018].

La PARRA LóPEZ, Emilio, La alianza de Godoy con los revolucionarios. (España y Francia a fines del siglo XVIII), Madrid, Consejo Superior de Investigaciones Científicas, 1992.

LA PARRA LÓPEZ, Emilio, «La orientación de la política exterior. El rey y los secretarios de Estado», en Antonio Morales Moya (coord.), 1802, España entre dos siglos. Vol. 2: Monarquía, Estado, Nación, Madrid, Sociedad Estatal de Conmemoraciones Culturales, 2003: 221-236.

LA PARra LóPEZ, Emilio, Manuel Godoy. La aventura del poder, Barcelona, Tusquets, 2005.

LA PARRA López, Emilio, «La defensa de la monarquía», en Elena de Lorenzo Álvarez (ed.), La época de Carlos IV (1788-1808): Actas del IV Congreso Internacional de la Sociedad Española de Estudios del Siglo XVIII, Gijón, Ediciones Trea, 2009: 41-54.

POMPONI, Francis, «Du Consulat à l'Empire: la Toscane dans la géostratégie napoléonienne (1801-1807)», en Marco Manfredi (ed.), Spagnoli a Palazzo Pitti il Regno d'Etruria (1801-1807): Atti del convegno internazionale di studi, Florencia-Pisa, 29 noviembre - 1 diciembre 2007, Florencia, Consiglio regionale della Toscana/Università di Pisa/Gabinetto G.P., Vieusseux, 2013: 37-59. RAO, Anna M., «Manuel Godoy e l'Italia», en Miguel Ángel Melón Jiménez, Emilio La Parra López y Fernando Tomás Pérez González (coords.), Manuel Godoy y su tiempo: Congreso Internacional Manuel Godoy (1767-1851), t. I, Badajoz, Editorial Regional de Extremadura, 2003a: 587-605.

RAO, Anna M., «La politica italiana della monarchia spagnola dal 1789 alla pace di Amiens», en Antonio Morales Moya (coord..), 1802, España entre 
Carlos IV y el ducado de Parma en tiempos de revolución (1796-1801), con el trasfondo de la cuestión de la Luisiana

dos siglos. Vol. 2: Monarquía, Estado, Nación, Madrid, Sociedad Estatal de Conmemoraciones Culturales, 2003b: 299-322.

Ruiz Alemán, Joaquín, Floridablanca. Escritos políticos. La Instrucción y el Memorial, Murcia, Academia Alfonso X el Sabio, 1982.

Seco Serrano, Carlos, Godoy, el hombre y el político, Madrid, Espasa-Calpe, 1978.

SeCo Serrano, Carlos, «La política exterior de Carlos IV», en Miguel Batllori i

Muné (coord.), La época de la Ilustración. Vol. 2: Las Indias y la política exterior, Madrid, Espasa-Calpe, 1988: 449-732. 